\title{
Why strengthening primary health care is essential to achieving universal health coverage
}

\author{
Chris van Weel MD PhD, Michael R. Kidd AM
}

Cite as: CMAJ 2018 April 16;190:E463-6. doi: 10.1503/cmaj.170784

See related article at www.cmaj.ca/lookup/doi/10.1503/cmaj.180186

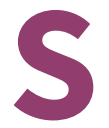

trengthening primary health care ${ }^{1}$ and the attainment of universal health coverage $\mathrm{e}^{2,3}$ are both important current global health policy initiatives. Primary health care is essential and affordable care that is accessible to everyone in the community, and includes health promotion, disease prevention, health maintenance, education and rehabilitation. ${ }^{4}$ The concept of universal health coverage, as noted in the United Nations' 2015 Sustainable Development Goals, is an aspiration to provide all people with access to essential high-quality health services and to safe, effective and affordable medicines and vaccines, while ensuring financial risk protection by providing care regardless of a person's ability to pay for it. ${ }^{2,5}$ It is clear from these two definitions that there is overlap between the aims of primary health care and universal health coverage; indeed, many have noted that primary health care is essential to achieving universal coverage. ${ }^{6,7}$

The two agendas have developed largely independently of each other, and yet the goal of both is to see healthier people living in healthier communities. There seems to be a natural synergy between the two. Yet the World Bank, the Bill and Melinda Gates Foundation and the World Health Organization (WHO) have referred to primary health care as a "black box" for policymakers ${ }^{8}$ - complex, mysterious and difficult to understand. Many health care policy-makers and funders have a poor understanding of primary health care, finding it difficult to quantify and assess its contributions to health systems. Here, we shine a light into the "black box." We emphasize the importance of performance indicators to monitor health system reform to show how strong primary health care contributes to the realization of universal health coverage.

\section{What is the difference between primary care and primary health care?}

A core aspect of primary health care is that it operates in the local community and seeks to address all health problems of all people. ${ }^{4,9,10}$ Strong primary health care relies on easy and convenient access to a trusted provider or team of providers. The term "primary care" usually refers to a focus on the health problems of an individual. ${ }^{1,4,11}$ Primary health care encompasses a wider

\section{KEY POINTS}

- Primary health care addresses the health needs of all patients at the community level, integrating care, prevention, promotion and education.

- Primary health care improves the performance of health systems by lowering overall health care expenditure while improving population health and access.

- The aims of primary health care overlap with those of universal health coverage, which aims to ensure access to essential health services and safe, effective and affordable essential medicines and vaccines for all people.

- To achieve universal health coverage, reforms should focus on strengthening primary health care to ensure equity and cost containment.

- Health system reforms should be monitored with indicators that reflect the core characteristics of primary health care: continuity of care, person- and population-centredness, coordination of care, prevention, health promotion and patient autonomy.

population focus. The distinction between the two is not clearcut because both terms imply a strong emphasis on prevention, health promotion, education and support delivered in a comprehensive manner. In countries with historically strong primary care, such as the United Kingdom, Denmark and the Netherlands, ${ }^{12}$ what is referred to as primary care has broadened in recent decades. Single-physician family practices have shifted to a model of multidisciplinary teams with shared responsibility for the care of target populations. Investment in primary health care in these countries has resulted in more care provided at the community level, and has improved integration of primary care with public health, specialist- and hospital-based care. Thus, the distinction between primary care and primary health care has been blurred. Emphasizing primary health care's focus on the individual is important, because people with seemingly identical health problems may have distinctly different needs, ${ }^{13}$ which may become increasingly complex if a patient has multiple chronic health problems. ${ }^{14}$ 


\section{What is the impact of robust systems of primary health care?}

Since the 1978 Declaration of Alma-Ata, ${ }^{15}$ which was reinforced by further resolutions of the World Health Assembly, ${ }^{16}$ the WHO has promoted primary health care as a core component of health systems. ${ }^{1}$ International comparisons of individual countries' performance in population health in relation to their health expenditure and aspects of health care processes and structures have helped us to understand the benefits of effective and efficient primary health care. Starfield's landmark publication in 1994, ${ }^{12}$ followed by research from Europe, Canada, the United States and other high-, low- and middle-income countries, has confirmed that health systems with strong primary health care at their core have lower health costs, better population health, higher patient satisfaction, fewer unnecessary hospital admissions and greater socioeconomic equity. ${ }^{17-20,}$ In addition, these systems have better rates of screening and follow-up for important diseases and are better at addressing the needs of patients with multimorbidity. ${ }^{21}$

\section{How can strong primary health care be achieved?}

Strengthening primary health care represents a fundamental shift from health care delivery focused on treating disease toward health systems that address the specific health needs of patients and communities, with a predominant focus on generalism, comprehensiveness and continuity of care (Box 1)., ${ }^{1,4,22}$ No one size fits all. The process must account for the historical, social, cultural and economic features that shape a country's health system. Primary health care also represents a shift from supply-driven to needs-driven care, toward person-centred support to patients facing the challenges of everyday life, and to people-centred support of communities to strengthen social cohesion and encourage greater resilience. ${ }^{9,23}$ Inherent in strong primary health care is reduced reliance on professional care by supporting people to develop and maintain autonomy and to take responsibility for aspects of their own health.

Box 1: Criteria that must be fulfilled to strengthen primary health care c $^{1,22}$

- Care provided must be comprehensive (i.e., address all health problems in all patients at all stages of life) and continuous over time.

- Care must be accessible in the local community.

- Gate keepers and coordinators are needed to assist patient referral, when needed, to other health care providers and services.

- Patients should be registered with an individual provider or practice, allowing care to be provided to an identified population of patients over time.

- Training must be based predominantly in primary care settings.

- Health policy support, including equitable payment of primary health care providers compared with their colleagues working in hospitals or in other areas of specialization, is required.
It is important to note that not every country with a strong system of primary health care realizes all of its benefits. For example, only some countries judged to have strong primary health care realized greater efficiency of health care through avoidance of unnecessary hospital admissions and clinical interventions. ${ }^{19}$ Political and cultural context in individual countries may affect the overall cohesion and integration of health service functions and thereby affect the implementation of policy.

Much attention has been paid to the relationship of strong primary health care to a nation's total health expenditure. Although health systems research done at the end of last century ${ }^{12,17,18}$ reported lower costs in countries with stronger primary health care, more recent European studies have not been able to replicate this finding. ${ }^{19}$ However, countries with strong primary health care, such as the UK and the Netherlands, may have invested more in their health systems in recent years, after long periods of limited expenditure in the 1980s and 1990s. We contend that this finding is more a result of national policies of savings and investments rather than the performance of primary health care. Reviewing developments over time with sophisticated indicators to allow comparison between health systems in different countries is important.

A limitation of international comparison studies is the quality of available data, particularly information about primary health care structures and performance. As a consequence, reliable data from well-researched countries like Canada, the UK, Denmark and the Netherlands could dominate the results at the expense of data from countries going through recent health system reforms, but where investment in research may be lacking. Standardization of data and the on-going use of data in the monitoring of primary health care policy, as proposed by the Primary Health Care Performance Initiative of the World Bank, the Bill and Melinda Gates Foundation and $\mathrm{WHO},{ }^{8}$ should provide more robust information for comparisons between all countries, including low- and middle-income countries.

\section{How can strong primary health care help with realizing universal health coverage?}

To achieve universal health coverage, three objectives must be met: everyone - including the poor and patients with the greatest health needs - must have access to care; the health care must be of good quality; and accessing health care should not be prevented by financial barriers. Universal health coverage is expected to increase the use of health care facilities by members of lower socioeconomic groups, which might be expected to increase health care expenditure in the short to medium term, given that people with high unmet health needs will begin to access care..$^{24,25}$ Anticipating spending increases could deter governments from making the investment required to achieve universal health coverage, which is why health care reform needs to be understood and committed to over the long term, with a particular focus on strengthening primary health care. Strong primary health care will improve population health through integration of primary care services with public health, thus lowering overall health care expenditure over time, improving the performance of the health 
care system and ensuring the provision of improved equity and access for everyone. ${ }^{9}$ The improved efficiency and cost-effectiveness of care are found in enduring and substantial savings in other parts of health care provision. This result is expected in all countries but is particularly important in low- and middle-income countries with limited resources and economic constraints. Healthier populations ${ }^{18,19}$ develop more resilient and socioeconomically viable communities ${ }^{23,24}$ that in turn increase the resources available to invest in future services, including health care for all. This is why primary health care should be regarded as a core component in realizing the ambitions of universal coverage as a sustainable development. ${ }^{2,6,7}$

\section{What is the best way to achieve universal health coverage by strengthening primary health care?}

Implementation of primary health care and universal health coverage has to take place under prevailing conditions; as a consequence, approaches will differ between countries. Financial demands from previous investments in hospitals and specialist services in many countries may hamper the reallocation of funds within health budgets to primary health care, which can be particularly problematic for low- and middle-income countries. ${ }^{22}$ Health policy in many nations is often restricted to the publicly funded health sector, although much health care may be provided privately ${ }^{22,26}$ and outside the influence of government-led policies. For example, India has to cope not only with limited health resources for its vast population, but with considerable societal resistance to the principle of health insurance. ${ }^{26}$

Solutions must fit the local socioeconomic and political situation. The UK introduced, and later abolished, fund holding ${ }^{27}$ and a quality and outcome framework ${ }^{28}$ for primary care, approaches that Denmark and the Netherlands, with similar health care systems, have not implemented. Although the role of the public sector is becoming more prominent in health care in the Netherlands, the country has moved to private health insurance while managing to contain health expenditure. ${ }^{29}$ Canadian primary health care has seen the recent introduction of innovations such as greater support for interprofessional primary health care teams, greater adoption of electronic medical records, a strong focus on quality improvement in family medicine $e^{30,31}$ and greater focus on the management of complex health needs through the pan-Canadian SPOR (Strategy for Patient-Oriented Research) Network in Primary and Integrated Health Care Innovations. ${ }^{32}$ International comparisons of primary health care reforms aim to understand the general principles adopted, and the lessons that can be learned from changes taking place under prevailing conditions in each country. However, there is no single ideal set of interventions.

In seeking to attain universal health coverage, the development of sustainable primary health care should continue to be the health policy priority of every nation. ${ }^{1,3}$ Implementation of primary health care should be supported by research to improve understanding of how, and to what extent, strengthening it can be done under the prevailing socioeconomic and cultural conditions of the country, and how these conditions will affect the likely costs and efficiency

\section{Box 2: Indicators of primary health care $^{4,33}$}

- Geographic spread, availability and accessibility of primary health care facilities for patients and communities, with special emphasis on

- people living in rural and remote locations

- vulnerable and marginalized groups

- Ability of patients to identify their personal primary health care providers

- Ability of providers to define the population they serve

- Multidisciplinary composition of primary health care services

- Role of primary health care professionals in coordinating all health problems, including

- acting as gatekeepers for referral to more specialized services and facilities

- involvement in follow-up and on-going care

- Integration of mental health into primary health care

- Collaboration with other health and support service providers in the community to promote health and well-being of all people

- Equitable income for professionals working in primary health care compared with those working in hospitals and other areas of specialty care

- Training of providers in community settings

of future health care provision. ${ }^{8}$ To show the effect of investments in primary health care, the success of implementation of interconnected reforms in health systems must be monitored. Indicators need to be developed and applied ${ }^{4,33}$ that show the contributions of primary health care (Box 2) and capture characteristics such as continuity of care, person- and population-centredness, coordination of care between health sectors, prevention, health promotion and support for patient autonomy, and a mechanism for data collection must be established. Monitoring these contributions ${ }^{8}$ will assist policy-makers to appreciate the contributions made by primary health care toward the attainment of universal health coverage, and support the ongoing investments needed to strengthen and reinforce strong primary health care.

\section{References}

1. The World Health Report 2008 - primary health care (now more than ever). Geneva: World Health Organization; 2008. Available: www.who.int/whr/2008/ en/ (accessed 2017 May 1).

2. Universal health coverage. Sustainable Developmental Goal 3: Health. Geneva: World Health Organization; 2017. Available: http://www.who.int/universal_ health_coverage/en/ (accessed 2017 May 1).

3. Sustainable development goals: 17 goals to transform our world. Geneva: United Nations; 2015. Available: www.un.org/sustainabledevelopment/sustainable -development-goals/ (accessed 2017 May 1).

4. Kidd M, editor. The contribution of family medicine to improving health systems: a guidebook from the World Organization of family doctors. 2nd ed. London (UK), New York: Radcliffe Publishing; 2013.

5. Jha A, Godlee F, Abbasi K. Delivering on the promise of universal health coverage. BMJ 2016;353:i2216.

6. Stigler FL, Macinko J, Pettigrew LM, et al. No universal health coverage without primary health care. Lancet 2016;387:1811.

7. Consideration of the recommendations on strengthening community-based health-care services - SEA/RC68/17. New Delhi (India): World Health Organization Regional Office for South-East Asia; 2015.

8. Measuring PHC: the measurement gap. Primary Health Care Performance Initiative; 2015. Available: phcperformanceinitiative.org/about-us/measuring-phc (accessed 2017 May 1). 
9. Art B, De Roo L, De Maeseneer J. Towards unity for health utilising communityoriented primary care in education and practice. Educ Health (Abingdon) 2007;20:74.

10. The European definition of general practice/family medicine. Ljubljana (Slovenia): WONCA Europe Secreteriat, Institute for Development of Family Medicine; 2011. Available: www.woncaeurope.org/sites/default/files/documents/Definition \%203rd\%20ed\%202011\%20with\%20revised\%20wonca\%20tree.pdf (accessed 2017 May 1).

11. Institute of Medicine. Primary care: America's health in a new era. Washington: National Academy Press; 1996.

12. Starfield B. Is primary care essential? Lancet 1994;344:1129-33.

13. olde Hartman TC, van Ravesteijn H, Lucassen $\mathrm{P}$, et al. Why the "reason for encounter" should be incorporated in the analysis of outcome of care. Br J Gen Pract 2011;61:e839-41.

14. Barnett K, Mercer SW, Norbury M, et al. Epidemiology of multimorbidity and implications for health care, research, and medical education: a crosssectional study. Lancet 2012;380:37-43.

15. Declaration of Alma-Alta. Proceedings of the International Conference on Primary Health Care; 1978 Sept. 6-12; Alma-Alta, USSR. Geneva: World Health Organization. Available: www.who.int/publications/almaata_declaration_en.pdf (accessed 2017 May 1).

16. Primary health care, including health system strengthening. Proceedings of the sixty-second World Health Assembly. Resolution WHA62.12; 2009 May 22. Geneva: World Health Organization. Available: http://www.who.int/hrh/ resources/A62_12_EN.pdf (accessed 2017 Oct. 24).

17. Starfield B, Shi L, Macinko J. Contribution of primary care to health systems and health. Milbank Q 2005;83:457-502.

18. Macinko J, Starfield B, Shi L. The contribution of primary care systems to health outcomes within Organization for Economic Cooperation and Development (OECD) countries, 1970-1998. Health Serv Res 2003;38:831-65.

19. Kringos D. The strength of primary care in Europe [thesis]. Utrecht (The Netherlands): Nivel; 2012. Available: www.nivel.nl/sites/default/files/bestanden/ Proefschrift-Dionne-Kringos-The-strength-of-primary-care.pdf (accessed 2017 May 1).
20. Schäfer WLA. Primary care in 34 countries: perspectives of general practitioners and their patients [thesis]. Utrecht (The Netherlands): Nivel; 2016. Available: www.nivel.nl/sites/default/files/bestanden/w-schafer-pc34.pdf (accessed May 1, 2017).

21. Stange KC, Ferrer RL. The paradox of primary care. Ann Fam Med 2009;7:293-9.

22. van Weel C, Kassai R. Expanding primary care in South and East Asia. BMJ 2017;356:j634.

23. De Maeseneer J, van Weel C, Daeren L, et al. From "patient" to "person" to "people": the need for integrated, people centered health care. Int J Pers Cent Med 2012;2:601-14.

24. De Maeseneer J, Willems S, De Sutter A, et al. Primary health care as a strategy for achieving equitable care: a literature review commissioned by the Health systems Knowledge Network. Geneva: World Health Organization; 2007. www.who.int/ social_determinants/resources/csdh_media/primary_health_care_2007_en.pdf? ua $=1$ (accessed 2016 May 1 ).

25. Watt G. The inverse care law today. Lancet 2002;360:252-4.

26. van Weel C, Kassai R, Qidwai W, et al. Primary healthcare policy implementation in South Asia. BMJ Glob Health 2016;1:e000057.

27. Kay A. The abolition of the GP fundholding scheme: a lesson in evidence-based policy making. Br J Gen Pract 2002;52:141-4.

28. Roland M, Guthrie B. Quality and outcomes framework: what have we learnt? BMJ 2016;354:i4060.

29. Kroneman M, Boerma W, van den Berg M, et al. The Netherlands: health system review. Health Syst Transit 2016;18:1-240.

30. Hutchison B, Levesque J-F, Strumpf E, et al. Primary health care in Canada: systems in motion. Milbank Q 2011;89:256-88.

31. Hutchison B, Glazier R. Ontario's primary care reforms have transformed the local care landscape, but a plan is needed for ongoing improvement. Health Aff (Millwood) 2013;32:695-703.

32. Pan-Canadian SPOR Network in Primary and Integrated Health Care Innovations. Ottawa: Canadian Institutes of Health Research; 2017 (modified). Available: www. cihr-irsc.gc.ca/e/49554.html (accessed 2017 Oct. 24).

33. Pettigrew LM, De Maeseneer J, Anderson MI, et al. Primary health care and the Sustainable Development Goals. Lancet 2015;386:2119-21.

\section{Competing interests: None declared.}

This article was solicited and has been peer reviewed.

Affiliations: Department of Primary and Community Care (van Weel), Radboud University Medical Center, Nijmegen, The Netherlands; Department of Health Services Research and Policy (van Weel), Australian National University, Acton, Australia; Department of Family and Community Medicine (Kidd), University of Toronto, Toronto, Ont.; Murdoch Childrens Research Institute (Kidd), Melbourne, Australia; South- gate Institute for Health, Equity and Society (Kidd), Flinders University, Adelaide, Australia

Contributors: Chris van Weel developed the concept outline of the paper, wrote the first concept of the paper and drafted the final version of the paper. Michael Kidd commented and redrafted the concept outline, commented and redrafted the concept version of the paper and approved its final version.

Correspondence to: Chris van Weel, chris.vanweel@radboudumc.nl 